\title{
Pengaruh Kecerdasan Berpikir Positif dan Kecerdasan Adversity Terhadap Kemampuan Berpikir Kritis Ilmu Pengetahuan Alam Pada Siswa SD Kelas IV
}

\author{
Yadi Heryadi \\ Program Studi Pendidikan Guru Sekolah Dasar, STKIP Setia Budhi Rangkasbitung, Jl. Budi Utomo No. \\ 22L Rangkasbitung Lebak, Banten \\ Corresponding Email : heryadi.yadio7@gmail.com
}

\begin{abstract}
ABSTRAK
Tujuan umum dari penelitian ini adalah untuk mengetahui dan menganalisis secara empiris pengaruh langsung kecerdasan berpikir positif terhadap kemampuan berpikir IPA siswa dan kecerdasan Adversity siswa terhadap kemampuan berpikir kritis Ilmu Pengetahuan Siswa. Penelitian ini dilakukan dengan menggunakan analisis jalur. Adapun sampel berjumlah 9o orang siswa Kelas IV SD Negeri di wilayah Kecamatan Cikulur Kabupaten Lebak, Banten. Dari hasil penelitian diperoleh kesimpulan bahwa : 1) Terdapat pengaruh langsung yang signifikan kecerdasan berpikir positif terhadap kecerdasan Adversity siswa. Besarnya kontribusi kecerdasan berpikir positif terhadap kecerdasan Adversity adalah $64,8025 \%$ sisanya sebesar 35,1975\% dipengaruhi oleh faktor lain diluar kecerdasan Adversity. 2) Terdapat pengaruh langsung yang tidak signifikan kecerdasan berpikir positif terhadap berpikir kritis IPA siswa. Besarnya kontribusi kecerdasan berpikir positif terhadap kemampuan berpikir kritis IPA o,6889\% sisanya sebesar 99,3111\% dipengaruhi oleh faktor lain diluar kemampuan berpikir kritis IPA. 3) Terdapat pengaruh langsung yang signifikan kecerdasan Adversity terhadap berpikir kritis IPA siswa. Besarnya kontribusi kecerdasan Adversity terhadap kemampuan berpikir kritis IPA 32,6041\% sisnya sebesar $67,3959 \%$ dipengaruhi oleh faktor lain diluar kemampuan berpikir kritis IPA. 4) Terdapat pengaruh tidak langsung yang signifikan kecerdasan berpikir positif terhadap berpikir kritis IPA melalui kecerdasan Adversity siswa. Besarnya 45,9566\% sisanya sebesar 54,0345\% dipengaruhi oleh faktor lain.
\end{abstract}

\section{Kata Kunci}

Kecerdasan Berpikir Positif, Kecerdasan Adversity, Kemampuan Berpikir Kritis IPA Siswa

\begin{abstract}
The general objective of this research is to find out and analyze empirically the direct effect of positive thinking intelligence on students' science thinking skills and students' adversity intelligence on students' critical thinking skills. This research was conducted using path analysis. The sample consisted of 90 Grade IV students at public elementary schools in the Cikulur District, Lebak Regency, Banten. From the research results, it can be concluded that: 1) There is a significant direct effect of positive thinking intelligence on students' Adversity intelligence. The contribution of positive thinking intelligence to Adversity intelligence is $64.8025 \%$, the remaining $35.1975 \%$ is influenced by other factors outside Adversity intelligence. 2) There is an insignificant direct effect of positive thinking intelligence on students' science critical thinking. The contribution of positive thinking intelligence to science critical thinking skills is $0.6889 \%$, the remaining $99.3111 \%$ is influenced by other factors outside science critical thinking skills. 3) There is a significant direct effect of Adversity intelligence on students' critical thinking in science. The magnitude of the contribution of Adversity's intelligence to the ability to think critically in science is $32.6041 \%$, the other $67.3959 \%$ is influenced by other factors outside the ability to think critically in science. 4) There is a significant indirect effect of positive thinking intelligence on science critical thinking through students' Adversity intelligence. The amount is $45.9566 \%$, the remaining $54.0345 \%$ is influenced by other factors.
\end{abstract}

Keywords :

Positive Thinking Intelligence, Adversity Intelligence, Students' Science Critical Thinking Ability 


\section{A. PENDAHULUAN}

\section{Latar Belakang}

Pendidikan memiliki peranan sangat penting dalam proses mencerdaskan kehidupan bangsa. Sebab melalui pendidikan akan diprestasikan manusia-manusia terampil dan berkualitas sesuai dengan tujuan pendidikan nasional sehingga tercapailah masyarakat adil dan makmur. Pendidikan dikatakan berprestasi bila mengprestasikan perubahan yang positif baik dari segi pengetahuan, keterampilan, tingkah laku dan sikap pada diri siswa menuju kedewasaannya serta dapat digunakan dalam hidup bermasyarakat. Untuk itu siswa dilatih agar dapat mendayagunakan potensi yang ia miliki secara maksimal, melalui proses belajarmengajar di sekolah. Dalam pendidikan, kita mengenal ada 3(tiga) jenjang pendidikan yang berlaku di Indonesia, yaitu :

1. Pendidikan Menengah, yang terdiri dari SMA, SMK, dan MA.

2. Pendidikan Dasar, yang terdiri dari SD/MI, SMP/MTs

3. Pendidikan PAUD, Yang teriri dari TK dan sejenisnya

Pendidikan dasar merupakan salah satu jenjang pendidikan yang berlaku dalam sistem pendidikan Nasional. Penyelenggaraan pendidikan dasar merupakan suatu proses yang berlangsung selama 6 tahun untuk tingkat SD/MI dan 3 tahun untuk tingkat SMP/MTs. Dalam rangka melaksanakan program pendidikan serta untuk mencapai tujuan pendidikan nasional, penyelenggaraan pendidikan dasar dimana salah satunya adalah tingkat Sekolah Dasar (SD) merupakan suatu system. Sebagai suatu sistem pada hakikatnya penyelenggaraan pendidikan SD merupakan suatu keseluruhan yang meliputi komponen-komponen masukan, proses dan kelulusan. Dengan demikian ketiga komponen diatas merupakan komponen-komponen yang mendukung penyelenggaraan pendidikan di sekolah menengah pertama.

Dalam proses belajar mengajar, mata pelajaran IPA ini berisi materimateri yang bersifat teoritis dan praktek, oleh karena itu para siswa yang mengikuti mata pelajaran ini dituntut memiliki sejumlah kemampuan dalam memahami semua materi dan menyelesaikan soal-soalnya. Rasa takut terhadap pelajaran IPA (fobia IPA) sering kali menghinggapi perasaan siswa mulai dari tingkat dasar sampai perguruan tinggi dan rasa takut yang berlebihan terhadap IPA membuat siswa menjadi asing dan cenderung memusuhi pembelajaran IPA. Sikap dan persepsi negatif membuat kebiasaan belajar dan sikap pada pelajaran menjadi lebih buruk. Pada umumnya siswa mendengar pelajaran Ilmu Pengetahuan Alam (IPA) sudah gelisah, merasa tidak percaya diri karena Ilmu Pengetahuan Alam (IPA) adalah gabungan dari pelajaran Fisika, Biologi dan Kimia sehingga siswa mengganggap pelajaran Ilmu Pengetahuan Alam (IPA) itu adalah pelajaran yang sangat sulit. Belajar IPA, tanpa memahami konsep dan latihan yang kontinu tidak mungkin dikuasai sedangkan siswa biasanya enggan membaca dan mengerjakan latihan.

Pada hakikatnya, mata pelajaran IPA bukanlah mata pelajaran yang sulit dikuasai. Hanya saja dibutuhkan usaha lebih untuk mempelajarinya, salah satunya dengan mengembangkan kemampuan berpikir kritis siswa, dalam hal ini khusus dalam 
pelajaran IPA. Kemampuan berpikir kritis adalah keharusan dalam usaha menyelesaikan masalah, membuat keputusan, menganalisa asumsi-asumsi. Kemampuan berpikir kritis diterapkan kepada siswa untuk belajar memecahkan masalah secara sistematis, inovatif dan mendesain solusi yang mendasar. Dengan kemampuan berpikir kritis siswa menganalisis apa yang mereka pikirkan, mensintesis informasi dan menyimpulkannya. Kemampuan berpikir kritis dapat dikemabangkan dalam pembelajaran IPA karena IPA memiliki struktur dan kajian yang lengkap, serta jelas antar konsep. Aktivitas kemampuan berpikir kritis siswa dapat dilihat dari kemampuan siswa dalam penguasaan pengetahuan dan keterampilan secara lengkap dan sistematis. Tujuan pembelajaran IPA bagi siswa dapat tercapai jika saja guru dapat mengoptimalkan faktor-faktor yang mendukungnya, sedangkan faktorfaktor yang menjadi penghambat dapat diminimalisir dan bila mugkin dihilangkan.

Oleh karena itu, guru hendaknya harus mampu memilih dan menyesuaikan dengan tujuan, situasi dan kondisi serta materi yang akan disampaikan, terutama pada mata pelajaran IPA. IPA merupakan pelajaran yang sangat menarik untuk dipelajari karena banyak mempelajari tentang alam yang sudah pasti kebenarannya. Pada mata pelajaran IPA guru hendaknya tidak hanya menyampaikan materi secara ceramah saja, karena akan dapat menyebabkan siswa menjadi pasif dan siswa hanya mendengarkan apa yang disampaikan oleh gurunya saja tanpa berusaha aktif menggali informasi sendiri. IPA salah satu ilmu yang memiliki peranan untuk meningkatkan kemampuan berpikir kritis. Siswa memerlukan kemampuan berpikir kritis yang tinggi karena kemampuan berpikir kritis IPA berperan penting dalam penyelesaian suatu permasalahan mengenai pelajaran IPA. Karena kemampuan berpikir kritis adalah cara berpikir disiplin cerdasan dari konseptualisasi, penerapan, analisis, sintesis dan evaluasi yang menekankan pada basis kepercayaan. Melalui proses tersebut dihasilkan dari observasi, pengetahuan, pengalaman, refleksi dan penalaran atau pemikiran logis serta komunikasi. Proses tersebut juag menuntut adanya interpretasi dan pengambilan sebuah keputusan yang diyakini atau dilakukan.

Rendahnya kemampuan berpikir kritis IPA disebabkan oleh aktivitas dalam pembelajarannya yang sangat rendah. Hal ini dikarenakan pada pembelajaran IPA, siswa dituntut banyak membaca karena sebagian besar pembelajarannya bersifat teoritik dan diperlukan hafalan mengenai bahasa latin. Siswa jarang sekali mengajukan pertanyaan walaupun guru telah memancing dengan pertanyaanpertanyaan yang sekiranya siswa belum jelas. Dalam proses pembelajaran selama ini, guru senantiasa mendominasi aktivitas di kelas, sementara siswa dijadikan sebagai objek untuk menerima hal-hal yang dianggap penting pada saat pembelajaran berlangsing. Seseorang diharapkan mampu berpikir positif untuk mencapai hasil atau keputusan yang tepat dan bijaksana dengan kecerdasan yang dimiliki. Potensi siswa dapat juga ditentukan banyak faktor antara lain yaitu kecerdasan berpikir positif yang akan menentukan berapa persen dari potesni siswa yang mampu siswa capai. Dengan menaikkan cara kecerdasan berpikir positif siswa mampu mengubah kesulitan dan tantangan berat dalam 
hidup menjadi karunia dan peluang untuk meraih kesuksesan, kebahagiaan dan kedamaian yang lebih besar. Untuk itu diperlukan latihan yang berfokus pada salah satu atau kedua pikiran otot yang bisa secara dramatis menaikkan kecerdasan berpikir positif seseorang dalam waktu yang relatif singkat.

Dalam hal ini kecerdasan yang saat ini sering diperhitungkan ada tiga, yaitu Intellegence Quotient (IQ), Emotioan Quotient (EQ) dan Spiritual Quotient (SQ).Salah satu bagian dari kecerdasan yakni Adversity Quotient (AQ). Adversity Quotient (AQ) pertama kali dicetuskan pertama kali oleh Stoltz. Stoltz (2008 : 8) yang menyatakan "Suksesnya pekerjaan dan hidup anda terutama ditentukan oleh Adversity Quotient (AQ). Dari pernyataan tersebut dapat diartikan bahwa Adverity Quotient (AQ) merupakan bentuk kecerdasan yang melatarbelakangi kecerdasan seseorang dalam menghadapi sebuha tantangan, hambatan dan masalah di saat terjadi kesulitan atau kegagalan. Adversity Quotient (AQ) sering diidentikkan dengan daya juang untuk melawan kesulitan. Faktor Adversity Quotient (AQ) merupakan keinginan atau motivasi yang kuat dari dalam diri siswa. Keinginan yang muncul dari dalam diri seseorang diharapkan akan lebih menunjang keinginan diri seseorang tersebut, karena pada hakikatnya keinginan yang paling baik adalah yang keluar dari diri seseorang tu sendiri.

Keberhasilan siswa dalam kemampuan berpikir kritis tergantung bagaimana siswa tersebut bersikap konsisten. Siswa yang konsisten maka dia akan mampu menyelaraskan antara sikap dan perilakunya sampai pada tujuan yang diharapkan tercapai. Menurut Robbins (2010 : 41), "Konsistensi berarti setiap individu berusaha untuk menyelaraskna sikap dan perilaku agar terlihat rasional dan konsisten”. Konsistensi diri merupakan sikap seseorang yang tetap, selaras, sesuai dan teguh memegang prinsp yang diyakini untuk mencapau kehendak, minat, serta tujuan yang diinginkan. Ketika siswa bisa berpikir positif, fokus dan disiplin, maka konsistensi diri siswa akan tinggi. Konsistensi diri harus tetap dipupuk agar siswa mampu meraih hal yang diinginkan, dalam hal ini adalah kemampuan berpikir kritis. Siswa yang memiliki konsistensi diri yang baik dalam belajar akan dipastikan berimplikasi terhadap kemampuan berpikir kritis siswa itus sendiri. Keberhasilan siswa dalam kemampuan berpikir kritis tergantung pada bagaimana cara siswa berpikir positif dalam mengatasi kesulitan yang ada. Kecerdasan dipandang sebagai sesuatu yang relatif, sebab kecerdasan setiap individu berbeda-beda. Jika dikaitkan dengan cara berpikir positif, maka jenis kecerdasan yang digunakan kecerdasan berpikir positif, dikaitkan dengan mengatasi masalah, jenis kecerdasan yang digunakan kecerdasan adversity.

Berdasarkan uraian di atas, peneliti pada penelitian ini akan meneliti sejauh mana pengaruh kecerdasan berpikir positif dan kecerdasan adversity terhadap kemampuan berpikir kritis ipa siswa.

\section{B. METODE}

Penelitian ini dilakukan dengan menggunakan metode survey. Seperti yang dijelaskan Sugiyono (2009: 12), "Metode survey digunakan untuk mendapatkan data dari tempat tertentu yang alamiah (bukan buatan), tetapi peneliti melakukan perlakuan dalam pengumpulan data, misalnya dengan mengedarkan kuisioner, test, wawancara terstruktur dan sebagainya 
(perlakuan tidak seperti dalam eksperimen)".

Untuk mencapai tujuan penelitian, penulis menggunakan metode penelitian kuantitatif. Hal ini dikarenakan dalam pengambilan, pengumpulan, dan sampai memperoleh hasil datanya diperoleh dalam bentuk skor/angka.

Penelitian ini dilakukan dengan menggunakan metode survei dengan teknik analisis jalur (path analysis). Teknik analisis jalur adalah teknik yang digunakan untuk menguji besarnya sumbangan (kontribusi) yang ditunjukkan oleh koefisien jalur dari hubungan kausal antara variabel $\mathrm{X}_{1}, \mathrm{X}_{2}$ dan $\mathrm{X}_{3}$ terhadap $\mathrm{Y}$ serta dampaknya terhadap Z (Supardi, 2013:271).

Supardi (2013:271) menyatakan, "Analisi jalur ialah suatu teknik untuk menganalisis hubungan sebab akibat yang terjadi pada regresi berganda jika variabel bebasnya mempengaruhi variabel tergantung secara langsung tetapi juga secara tidak langsung”.
Variabel yang diteliti pada penelitian ini adalah :

a. Variabel Bebas (Eksogen)

- Kecerdasan Berpikir Positif

- Kecerdasan Adversitiy

b. Variabel Terikat (Endogen)

- Kemampuan Berpikit Kritis Untuk mengetahui hubungan antar variabel dalam penelitian ini, peneliti menyusun hubungan antar variabel dalam bentuk diagram jalur sebagai berikut:

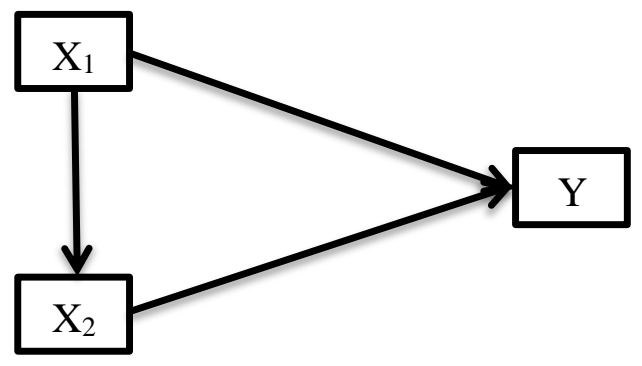

Gambar 1. Konstelasi Masalah

Keterangan :

$\mathrm{X}_{1}$ : Kecerdasan Bepikir Positif

$\mathrm{X}_{2}$ : Kecerdasan Adversity

$\mathrm{Y}$ : Kemampuan Berpikir Kritis IPA

\section{HASIL PENELITIAN}

Tabel 1. Uji Linearitas Hubungan Kecerdasan Berpikir Positif Terhadap Kecerdasan Adversity

\begin{tabular}{|c|c|c|c|c|c|c|c|}
\hline \multicolumn{8}{|c|}{ ANOVA Table } \\
\hline & & & $\begin{array}{l}\text { Sum of } \\
\text { Squares }\end{array}$ & Df & $\begin{array}{l}\text { Mean } \\
\text { Square }\end{array}$ & $\mathrm{F}$ & Sig. \\
\hline \multirow{5}{*}{$\begin{array}{l}\text { Kecerdasan } \\
\text { Berpikir } \\
\text { Positif* } \\
\text { Kecerdasan } \\
\text { Adversity }\end{array}$} & \multirow{3}{*}{$\begin{array}{l}\text { Between } \\
\text { Groups }\end{array}$} & (Combined) & 26644,350 & 44 & 605,553 & 4,702 & , ooo \\
\hline & & Linearity & 21016,432 & 1 & 21016,432 & 163,192 & , ooo \\
\hline & & $\begin{array}{l}\text { Deviation } \\
\text { from } \\
\text { Linearity }\end{array}$ & 5627,918 & 43 & 130,882 & 1,016 &, 478 \\
\hline & \multicolumn{2}{|c|}{ Within Groups } & 5795,250 & 45 & 128,783 & & \\
\hline & \multicolumn{2}{|l|}{ Total } & 32439,600 & 89 & & & \\
\hline
\end{tabular}


Tabel 2. Uji Linearitas Hubungan Kecerdasan Berpikir Positif Terhadap Kemampuan Berpikir Kritis IPA

\begin{tabular}{|c|c|c|c|c|c|c|c|}
\hline \multicolumn{8}{|c|}{ ANOVA Table } \\
\hline & & & $\begin{array}{l}\text { Sum of } \\
\text { Squares }\end{array}$ & Df & $\begin{array}{l}\text { Mean } \\
\text { Square }\end{array}$ & $F$ & Sig. \\
\hline \multirow{5}{*}{$\begin{array}{l}\text { Berpikir Kritis } \\
\text { IPA * } \\
\text { Kecerdasan } \\
\text { Berpikir } \\
\text { Positif }\end{array}$} & \multirow{3}{*}{$\begin{array}{l}\text { Between } \\
\text { Groups }\end{array}$} & (Combined) & 3072,206 & 48 & 64,004 & 1,673 & ,047 \\
\hline & & Linearity & 1365,495 & 1 & 1365,495 & 35,695 & , 000 \\
\hline & & \begin{tabular}{|l|} 
Deviation \\
from \\
Linearity \\
\end{tabular} & 1706,710 & 47 & 36,313 & 949 & ,5 \\
\hline & \multicolumn{2}{|l|}{ Within G } & 1568,417 & 41 & 38,254 & & \\
\hline & \multicolumn{2}{|l|}{ Total } & 4640,622 & 89 & & & \\
\hline
\end{tabular}

Tabel 3. Uji Linearitas Hubungan Kecerdasan Adversity

Terhadap Kemampuan Berpikir Kritis IPA

\begin{tabular}{|c|c|c|c|c|c|c|c|}
\hline \multicolumn{8}{|c|}{ ANOVA Table } \\
\hline & & & $\begin{array}{l}\text { Sum of } \\
\text { Squares }\end{array}$ & $\mathrm{Df}$ & $\begin{array}{c}\text { Mean } \\
\text { Square }\end{array}$ & $F$ & Sig. \\
\hline \multirow{5}{*}{$\begin{array}{l}\text { Berpikir Kritis } \\
\text { IPA * } \\
\text { Kecerdasan } \\
\text { Adversty }\end{array}$} & \multirow{3}{*}{$\begin{array}{l}\text { Between } \\
\text { Groups }\end{array}$} & (Combined) & 3267,172 & 44 & 74,254 & 2,433 & ,002 \\
\hline & & Linearity & 1886,437 & 1 & 1886,437 & 61,808 & , ooo \\
\hline & & $\begin{array}{l}\text { Deviation } \\
\text { from } \\
\text { Linearity }\end{array}$ & 1380,735 & 43 & 32,110 & 1,052 & ,433 \\
\hline & \multicolumn{2}{|c|}{ Within Groups } & $1373,45^{\circ}$ & 45 & 30,521 & & \\
\hline & \multicolumn{2}{|c|}{ Total } & 4640,622 & 89 & & & \\
\hline
\end{tabular}

Tabel 4. Koefisien Jalur $P_{21}$

\begin{tabular}{|c|c|c|c|c|c|c|}
\hline \multicolumn{7}{|c|}{ Coefficients $^{a}$} \\
\hline \multirow{2}{*}{\multicolumn{2}{|c|}{ Model }} & \multicolumn{2}{|c|}{$\begin{array}{l}\text { Unstandardized } \\
\text { Coefficients }\end{array}$} & \multirow{3}{*}{\begin{tabular}{c|}
$\begin{array}{c}\text { Standardize } \\
\mathrm{d} \\
\text { Coefficients }\end{array}$ \\
Beta \\
\end{tabular}} & \multirow[t]{2}{*}{$\mathrm{T}$} & \multirow[t]{2}{*}{ Sig. } \\
\hline & & $\mathrm{B}$ & Std. Error & & & \\
\hline \multirow[b]{2}{*}{1} & (Constant) & $1,832 \mathrm{E}-105$ & ,o63 & & ,ooo & 1,000 \\
\hline & $\begin{array}{l}\text { Zscore: Kecerdasan } \\
\text { Berpikir Positif }\end{array}$ & ,805 & ,063 & ,805 & 12,724 & , ooo \\
\hline
\end{tabular}

Tabel 5. Koefisien Jalur $P_{31}$ dan $P_{32}$

\begin{tabular}{|c|c|c|c|c|c|c|}
\hline & & Coef & ficients $^{\mathrm{a}}$ & & & \\
\hline & & $\begin{array}{r}\text { Unstanc } \\
\text { Coeffi }\end{array}$ & $\begin{array}{l}\text { lardized } \\
\text { cients }\end{array}$ & $\begin{array}{c}\text { Standardize } \\
\mathrm{d}\end{array}$ & $\mathrm{T}$ & Sig. \\
\hline & & B & Std. Error & Beta & & \\
\hline & (Constant) & $\begin{array}{r}6,016 \mathrm{E}- \\
016\end{array}$ & ,082 & & , ooo & 1,000 \\
\hline 1 & \begin{tabular}{|l} 
Zscore: Kecerdasan \\
Berpikir Positif
\end{tabular} & , 083 & 139 & , o83 & ,598 &, 551 \\
\hline & $\begin{array}{l}\text { Zscore: Kecerdasan } \\
\text { Adversity }\end{array}$ & ,571 & 139 & ,571 & 4,109 & , OOO \\
\hline
\end{tabular}




\section{D.PEMBAHASAN}

Tabel 6.Deskripsi Data Penelitian Berpikir Kritis IPA

\begin{tabular}{|c|c|c|}
\hline \multicolumn{3}{|c|}{ Statistics } \\
\hline \multicolumn{3}{|c|}{ Berpikir Kritis IPA } \\
\hline \multirow{2}{*}{$\mathrm{N}$} & Valid & 90 \\
\cline { 2 - 3 } & Missing & $\mathrm{o}$ \\
\hline \multicolumn{2}{|c|}{ Mean } & 33,24 \\
\hline \multicolumn{2}{|c|}{ Median } & 34,00 \\
\hline \multicolumn{2}{|c|}{ Mode } & 34 \\
\hline Std. Deviation & 7,221 \\
\hline \multicolumn{2}{|c|}{ Minimum } & 14 \\
\hline Maximum & 48 \\
\hline
\end{tabular}

berikut:

Selanjutnya melihat gambar histogram dari skor berpikir kritis IPA sebagai

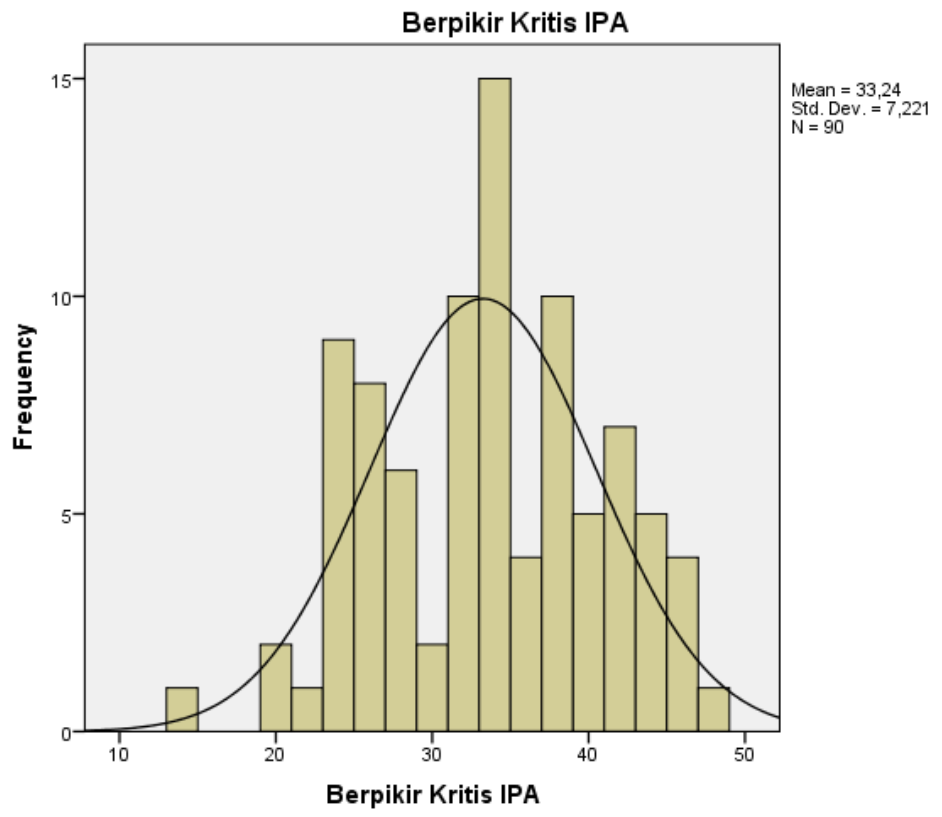

Gambar 2.

Histogram Poligon Variabel Berpikir Kritis IPA

Histogram merupakan gambaran dalam bentuk batang yang menunjukkan frekuensi dari masingmasing data yang diperoleh dalam penelitian ini berdistribusi normal, karena dari kurva mendekati bentuk kurva normal.

\section{A. Pengujian Persyaratan Analisis \\ 1. Uji Normalitas}

Guna menguji formalitas data masing-masing variabel, maka hipotesis yang digunakan adalah:

Hipotesis :

$\mathrm{H}_{\mathrm{o}}$ : Data berdistribusi normal

$\mathrm{H}_{1}$ : Data tidak berdistribusi normal

Kriteria Pengujian Hipotesis :
Tolak $\mathrm{H}_{\mathrm{o}}$ jika nilai probabilitas $\mathrm{p}>$ 0,05 berdasarkan pengujian dengan menggunakan Kolmogorof Smirnov pada SPSS 20.

Terima $\mathrm{H}_{\mathrm{o}}$ jika nilai probabilitas $\mathrm{p}<$ o,05 berdasarkan pengujian dengan menggunakan Kolmogorof Smirnov pada SPSS 20.

Uji normalitas dilakukan untuk mengetahui apakah data yang diperoleh peneliti berasal dari populasi berdistribusi normal atau tidak. Hal ini dilakukan sebagai syarat jika pengujian dengan menggunakan statistic parametrik. Dalam melakukan uji normalitas peneliti menggunakan SPSS 
20 sebagai alat bantu. Dalam hal ini peneliti menggunakan pengujian dengan menggunakan KolmogorovSmirnov.

\section{Uji Linearitas}

Uji linear dilakukan untuk mengetahui, membuktikan bahwa hubungan antar variabel yang diteliti memiliki hubungan yang linear. Dalam melakukan uji linear regresi antar variabel, peneliti melakukan analisis regresi dengan bantuan SPSS 20 dengan hasil sebagai berikut:

Tabel 7. Uji Linearitas Hubungan Kecerdasan Berpikir Positif Terhadap Kemampuan Berpikir Kritis IPA

\begin{tabular}{|c|c|c|c|c|c|c|c|}
\hline \multicolumn{8}{|c|}{ ANOVA Table } \\
\hline & & & $\begin{array}{l}\text { Sum of } \\
\text { Squares }\end{array}$ & $\mathrm{Df}$ & $\begin{array}{l}\text { Mean } \\
\text { Square }\end{array}$ & $\mathrm{F}$ & Sig. \\
\hline \multirow{5}{*}{$\begin{array}{l}\text { Berpikir Kritis } \\
\text { IPA * } \\
\text { Kecerdasan } \\
\text { Berpikir } \\
\text { Positif }\end{array}$} & \multirow[b]{3}{*}{$\begin{array}{l}\text { Between } \\
\text { Groups }\end{array}$} & (Combined) & 3072,206 & 48 & 64,004 & 1,673 & , 047 \\
\hline & & Linearity & 1365,495 & 1 & 1365,495 & 35,695 & , ooo \\
\hline & & $\begin{array}{l}\text { Deviation } \\
\text { from } \\
\text { Linearity }\end{array}$ & 1706,710 & 47 & 36,313 & ,949 & 571 \\
\hline & \multicolumn{2}{|c|}{ Within Groups } & 1568,417 & 41 & 38,254 & & \\
\hline & \multicolumn{2}{|l|}{ Total } & 4640,622 & 89 & & & \\
\hline
\end{tabular}

\section{Pengujian Multikolinearitas}

Uji multikolinieritas bertujuan untuk menguji apakah model regresi ditemukan adanya korelasi yang sempurna antarvariabel bebas (independent). Model regresi yang baik seharusnya tidak terjadi korelasi yang sempurna diantara variabel bebas. Salah satu cara untuk untuk mendeteksi adanya multikolinieritas adalah dengan melihat tolerance atau varian inflation factor (VIF). Apabila tolerance $<0,1$ atau nilai VIF $>10$ maka terjadi multikolinearitas.

Hipotesis

$\mathrm{H}_{\mathrm{o}}$ : Terjadi kolinieritas antara variabel bebas

$\mathrm{H}_{1}$ : Tidak terjadi kolinieritas antara variabel bebas

Kriteria pengujian kolinieritas:

a) Mempunyai nilai VIF disekitar angka 1

b) Mempunyai angka tolerance mendekati angka 1

Dengan menggunakan SPSS 20 diperoleh hasil sebagai berikut:

Tabel 8. Uji Multikolinearitas

\begin{tabular}{|l|l|l|l|}
\hline \multicolumn{5}{|c|}{ Coefficients $^{\mathbf{a}}$} \\
\hline \multirow{4}{*}{ Model } & \multicolumn{2}{|l|}{ Collinearity Statistics } \\
\cline { 3 - 5 } & Tolerance & VIF \\
\hline \multirow{4}{*}{1} & $\begin{array}{l}\text { (Constant) } \\
\text { Kecerdasan } \\
\text { Berpikit Positif }\end{array}$ & .352 & \\
\cline { 2 - 5 } & $\begin{array}{l}\text { Kecerdasan } \\
\text { Adversity }\end{array}$ & $\mathbf{2 , 8 4 0}$ & \\
& & & $\mathbf{2 , 8 4 0}$ \\
\hline
\end{tabular}

a. Dependent Variable: Berpikir Kritis IPA

\section{Pengujian Heteroskedastisitas}

Pengertian heteroskedastisitas adalah apabila kesalahan atau residual yang diamati tidak memiliki varian yang konstan. Kondisi heteroskedastisitas sering terjadi pada data cross section, atau data yang diambil dari beberapa responden pada suatu waktu tertentu.

Salah satu metode untuk mendeteksi adanya heteroskedastisitas adalah dengan membuat scatter-plot antara standardized Residual (ZRESID) 
dan Standardized Predicted Value (Y topi). Pada gambar dibawah ini menunjukkan tidak ada perubahan e sepanjang Y topi, maka dinyatakan tidak ada heteroskedastisitas pada galat (error/residual ) tersebut.

Tabel 9. Uji Normalitas Galat

\begin{tabular}{|c|c|c|}
\hline \multicolumn{3}{|c|}{ One-Sample Kolmogorov-Smirnov Test } \\
\hline & & $\begin{array}{c}\text { Unstandardized } \\
\text { Residual }\end{array}$ \\
\hline \multicolumn{2}{|l|}{$\mathrm{N}$} & 90 \\
\hline \multirow{2}{*}{ Normal Parameters ${ }^{\mathrm{a}, \mathrm{b}}$} & Mean & oE-7 \\
\hline & Std. Deviation & 5,55149736 \\
\hline \multirow{3}{*}{$\begin{array}{l}\text { Most Extreme } \\
\text { Differences }\end{array}$} & Absolute & .044 \\
\hline & Positive & .036 \\
\hline & Negative & -.044 \\
\hline \multicolumn{2}{|c|}{ Kolmogorov-Smirnov Z } & .416 \\
\hline \multicolumn{2}{|c|}{ Asymp. Sig. (2-tailed) } & .955 \\
\hline \multicolumn{3}{|c|}{ a. Test distribution is Normal. } \\
\hline \multicolumn{3}{|c|}{ b. Calculated from data. } \\
\hline
\end{tabular}

Dari table di atas menunjukkan bawha uji hipotesis yang menyatakan distribusi residual pada analisis regresi ini mengikuti distribusi normal. Hal ini ditunjukkan dengan nilai $\mathrm{Z}=0,416$ dan Sig. $=0,955>0,05$. Hal ini berarti asumsi atau persyaratan analisis regresi terpenuhi.

\section{E. KESIMPULAN}

Dari hasil analisis data lapangan pada uraian sebelumnya, maka dapat disimpulkan hal-hal sebagai berikut:

1. Terdapat pengaruh langsung yang signifikan kecerdasan berpikir positif terhadap kecerdasan adversity siswa SD Negeri di wilayah Kecamatan Cikulur, Lebak. Hal tersebut dibuktikan dengan perolehan nilai $\quad t_{\text {hitung }}(12,724)>$ $t_{\text {tabel }}(1,980)$. Besarnya kontribusi kecerdasan berpikir positif terhadap kecerdasan adversity adalah 64,8025\%, sisanya sebesar $35,1975 \%$ dipengaruhi oleh faktor lain di luar kecerdasan adversity.

\section{Pengujian Normalitas Galat}

Persyaratan regresi yang baik jika data penelitian mengikuti distribusi normal. 
$67,3959 \%$ dipengaruhi oleh faktor lain di luar kemampuan berpikir kritis IPA.

4. Terdapat pengaruh tidak langsung yang signifikan kecerdasan berpikir positif terhadap berpikir kritis IPA melalui kecerdasan adversity siswa SD Negeri di wilayah Kecamatan Cikulur, Lebak. Hal tersebut dibuktikan dengan perolehan nilai $t_{\text {hitung }}(4,26)>$ $t_{\text {tabel }}(1,980)$. Besarnya kontribusi kecerdasan berpikir positif terhadap kemampuan berpikir kritis IPA melalui kecerdasan adversity adalah 45,9566\%, sisanya sebesar $54,0345 \%$ dipengaruhi oleh faktor lainnya.

\section{DAFTAR PUSTAKA}

Abdullah, Suparman Ibrahim. 2013. Aplikasi Komputer Dalam Penyusunan Karya Ilmiah. Jakarta : Pustaka Mandiri

Aisyah, T.S 2008. Penerapan Strategi Konflik Kognitif dalam Pembelajaran Matematika untuk Meningkatkan Kemampuan Berpikir Kritis Siswa. Tesis. Jurusan
Pendidikan Matematika FKIP UNPAS : tidak diterbitkan.

Alawiyah, Septia. 2012. Hubungan Antara Adversity Quotient (AQ) dengan Prestasi Belajar Biologi. Skripsi. Unindra.

Arisworo, dkk. 2006. Ilmu Pengetahuan Alam. Bandung : Grapindo Media Pratama.

Aryana, I. B. P. 2007. Meningkatkan Keterampilan Berpikir Tingkat Tinggi Melalui Pembelajaran. Singaraja: UNDIKSHA

Bayani, Irma dan Hafizhoh Nur. 2011. Hubungan Antara Adversity Quotient dan Dukungan Sosial dengan Intensi Untuk Pulih dari Ktergantungan NAPZA Pada Penderita di Wilayah Bekasi Utara. Jurnal Soul. 4(2), 64-83.

Filsamime Dennis K. 2008. Menguak Berpikir Kritis dan Kreatif. Jakarta : Prestasi Pustaka.

Fisher, Roger. 2008. Getting to Yes: Teknik Berunding Tanpa Memaksakan Kehendak. Jakarta: Yayasan obor Indonesia.

Hans, Jen 2 A. 2006. Strategi Pengembangan Diri. Jakarta : Personal Development Training. Irena. 2014. Tips Trik Kilat Menciptakan Pikiran dan Kepribadian Positif. Yogyakarta: Pasarmu. 